\title{
Article
}

\section{Symmetrical Derivative of Anthrone as a Novel Receptor for Mercury Ions: Enhanced Performance of Modified Screen-Printed Electrode}

\author{
Karamjeet Kaur ${ }^{1}$, Susheel K. Mittal ${ }^{1, *}$, Ashok Kumar SK ${ }^{2}$, Ashwani Kumar ${ }^{3}$, Subodh Kumar ${ }^{3}$, \\ Jonathan P. Metters ${ }^{4}$ and Craig E. Banks ${ }^{4}$ (D)
}

Citation: Kaur, K.; Mittal, S.K.; Kumar SK, A.; Kumar, A.; Kumar, S.; Metters, J.P.; Banks, C.E. Symmetrical Derivative of Anthrone as a Novel Receptor for Mercury Ions: Enhanced Performance of Modified ScreenPrinted Electrode. C 2021, 7, 13. https://doi.org/10.3390/c7010013

Received: 10 December 2020

Accepted: 21 January 2021

Published: 27 January 2021

Publisher's Note: MDPI stays neutral with regard to jurisdictional claims in published maps and institutional affiliations.

Copyright: (c) 2021 by the authors. Licensee MDPI, Basel, Switzerland. This article is an open access article distributed under the terms and conditions of the Creative Commons Attribution (CC BY) license (https:// creativecommons.org/licenses/by/ $4.0 /)$.
1 School of Chemistry \& Biochemistry, Thapar Institute of Engineering \& Technology, Patiala 147001, India; karam86kaur@gmail.com

2 School of Advanced Sciences, VIT University, Vellore 632014, India; ashok312002@gmail.com

3 Department of Chemistry, GND University, Amritsar 143005, India; ashwanirubal@gmail.com (A.K.); subodh_gndu@yahoo.co.in (S.K.)

4 Faculty of Science and Engineering, School of Chemistry and the Environment Division of Chemistry and Environmental Science, Manchester Metropolitan University, John Dalton Building, Chester St. Manchester M1 5GD, UK; jpmetters@gmail.com (J.P.M.); craig.banks@gmail.com (C.E.B.)

* Correspondence: smittal@thapar.edu

\begin{abstract}
Voltammetric sensor using a symmetrical derivative of anthrone3 (1,7-diamino-3,9-dibutyl benzo[1,2,3-de:4,5,6-d'e']diquinoline-2,8(3H,9H)-dione) (SPE-A) has been developed as a probe for $\mathrm{Hg}$ (II) ions. Performance of the probe as screen-printed electrode modified with the receptor (SPE-A) has been compared with anthrone3 in solution phase, using 1:1 water-acetonitrile solvent system. Anthrone3 displayed an electrochemically quasi-reversible nature in voltammograms with both the systems and is presented as a novel disposable voltammetric sensor for mercury ions. Upon interaction with cations, both the electrode systems showed sensitivity towards $\mathrm{Hg}^{2+}$ ions with a lower detection limit of $0.61 \mu \mathrm{M}$. The magnitude of the voltammetric current with the SPE-A exhibited three times the current obtained with a bare glassy carbon electrode (GC). Kinetic performance of the SPE-A electrode is better than the GC electrode. The morphological studies indicate reusability of the electrodes.
\end{abstract}

Keywords: modified screen-printed electrode; anthrone derivative; voltammetric sensor for mercury ions; disposable chemical sensor; regeneration of SPE

\section{Introduction}

Heavy metal ions are essentially present in biological system but their excessive exposure and accumulation can lead to diseases with nervous and other systems [1-4]. Copper is the third most abundant essential heavy metal ion (after $\mathrm{Fe}^{3+}$ and $\mathrm{Zn}^{2+}$ ) present in the human body, playing an important role in fundamental physiological processes in organisms ranging from bacteria to mammals [5]. Nevertheless, as a metal pollutant, it is significantly responsible for a number of neurodegenerative diseases. Among other heavy metals that are highly toxic for human beings are the salts of mercury. Various mercuric salts have been used extensively by humans in the form of mercuric ointment as a remedy for skin and eye complaints. A major source of human exposure stems from a variety of natural and anthropogenic sources [6] and can lead, even at low concentration, to digestive, kidney, and especially neurological diseases [7]. The sensitive detection of mercuric ion is currently a task of prime importance for environmental or biological concerns along with other transition metal ions like $\mathrm{Ni}^{2+}, \mathrm{Cu}^{2+}, \mathrm{Zn}^{2+}$, and $\mathrm{Cd}^{2+}$.

The current and classical methods for the determination of copper and mercury include liquid phase chromatography, solid-phase extraction, atomic absorption spectroscopy 
(AAS), X-ray fluorescence, atomic fluorescence spectroscopy (AFS), atomic emission spectroscopy (AES), inductively coupled plasma mass spectroscopy (ICP-MS), and capillary electrophoresis (CE). These are well-established methods and are considered by their low detection limits (i.e., $0.02 \mathrm{ppb}$ for AAS; $0.001 \mathrm{ppt}$ for AFS; $0.01 \mathrm{ppt}$ for AES, and $0.08 \mathrm{ppt}$ for ICP-MS) [8]. However, these classical techniques are inconvenient, require expensive instrumentation, and are hardly portable.

Electrochemical analysis based on electrode modification is an interesting field used for heavy metal ion sensing $[9,10]$. Electrode modification with screen printing technology is now a well-established technique for both chemical and biosensors [11-14]. Screen printing has been developed over many years and one of its best known applications is the production of low-cost disposable glucose sensors for diabetics to monitor blood glucose levels [15-17]. There are lots of reports on modified SPEs for detection of heavy metal ions using stripping voltammetry. Bernalte et al. [18], used screen-printed gold electrodes for the determination of mercury by square wave anodic stripping voltammetry, while Hallam et al. $[19,20]$ reported electrochemical sensing of $\mathrm{Cr}(\mathrm{VI})$ with graphite screenprinted electrodes; for a full overview, see reference. Some recent reports on electrochemical sensors for mercury determinations include works of Raril and Manjunatha [21], Mikhail Vagin and Yakimova [22], Eksin et al. [23], and Ganjali et al. [24].

In this paper, we report the voltammetric behaviour of modified screen-printed electrodes of anthrone derivatives (SPE-A) towards different cations. There are no reports with anthrone molecule or its derivatives as voltammetric sensors. In addition, reports of SPE modified with synthesized organic molecule used for ion sensing purpose are rare [25]. Screen-printed electrodes modified with anthrone derivative as well as glassy carbon (GC) electrode have been used as voltammetric sensors for heavy metal ions. The modified SPE probe is selective towards $\mathrm{Hg}^{2+}$ ions and is far better in performance with regard to reproducibility and sensitivity than the performance of the GC-based probe. Performance of the electrode has been tested in different partially aqueous media. Amongst different compositions of solvents, water-acetonitrile in 1:1 ratio gives the best performance. SPEs are reported for the first time as reproducible voltammetric sensors after treatment with EDTA. Excellent performance of the anthrone derivative as a voltammetric sensor for $\mathrm{Hg}^{2+}$ ions is probably due to structural symmetry in the molecule, which makes it a stable molecule with a symmetrical cavity having four $\mathrm{N}$ atoms and available lone pairs. Surface morphology of screen-printed electrodes is also reported.<smiles>CCCCn1c(=O)c(N)c2c3cccc4c3c(c(N)c(=O)n4CCCC)c3cccc1c32</smiles>

1,7-diamino-3,9-dibutyl benzo[1,2,3-de:4,5,6-d'e']diquinoline-2,8(3H,9H)-dione (anthrone3).

\section{Experimental Section}

\subsection{Apparatus and Reagents}

All cyclic voltammograms (CV) were recorded on potentiostat-galvanostat (Autolab/ PGSTAT12/Eco-Chemie, Utrecht, The Netherlands). Surface morphology of the modi- 
fied electrode was examined by Scanning Electron Microscopy (SEM JEOL JSM-6610LV, Tokyo, Japan. Solvent (acetonitrile) was of HPLC grade (Merck, Germany) and used as obtained. Potassium chloride (Sigma Aldrich, St. Louis, MO, USA) $0.1 \mathrm{M}$ was used as a supporting electrolyte in all the experiments. HEPES buffer was used to maintain $\mathrm{pH}$. Ethylenediaminetetraacetic acid (EDTA) used was of analytical grade (Sigma Aldrich, St. Louis, MO, USA).

\subsection{Metal Ion Detection}

For cation interaction studies, perchlorate salts (Sigma Aldrich, St. Louis, MO, USA) of different metals $\left(\mathrm{Co}^{2+}, \mathrm{Ni}^{2+}, \mathrm{Cu}^{2+}, \mathrm{Zn}^{2+}, \mathrm{Hg}^{2+}\right.$, and $\mathrm{Pb}^{2+}$ ions) were used by preparing stock solution of concentration $10^{-2} \mathrm{M}$ in acetonitrile. Nitrogen gas was used for making the solution inert before every experiment.

\subsection{Interference Studies}

Studies for interference were carried out by adding 10 times the concentration, i.e., $1 \times 10^{-3} \mathrm{M}$ of metal ions like $\mathrm{Cu}^{2+}, \mathrm{Ni}^{2+}, \mathrm{Zn}^{2+}, \mathrm{Co}^{2+}$, and $\mathrm{Pb}^{2+}$ to that of $\mathrm{Hg}^{2+}$ ions $\left(10^{-4} \mathrm{M}\right)$.

\subsection{Synthetic Sample for Analysis}

Synthetic samples were prepared from nitrate salt of mercury of different concentrations in the range of $10^{-5}$ to $10^{-4} \mathrm{M}$, which were verified with atomic absorption spectroscopy (AAS) and SPE-A using cyclic voltammetry.

\subsection{Screen-Printed Electrode Preparation}

Screen-printed carbon electrodes were fabricated in-house with appropriate stencil designs using a microdek 1760RS screen printing machine (DEK, London, UK). The multistage printing process involved the sequential deposition of carbon graphite, silver-silver chloride, and dielectric inks (obtained from Gwent, Pontypool, UK) onto a polyester substrate material. Further modification of the working surface was carried out by mixing together anthrone3 within the carbon-graphite ink and placed into a fan oven for $15 \mathrm{~min}$ at $40{ }^{\circ} \mathrm{C}$ to dry. A three-electrode connector was used to efficiently connect the SPE with the potentiostat. When the screen-printed electrodes were used with the screen-printed silver-silver chloride reference electrode to conduct measurements, $40 \mu \mathrm{L}$ of the desired buffer solution was applied onto the electrode surface with the aid of a micropipette. Cyclic voltammograms were recorded at 10 different scan rates from 20 to $1000 \mathrm{mV} \mathrm{s}^{-1}$ by potential cycling between 0.0 and $+1100 \mathrm{mV}$. The electrochemical measurements were carried out at a temperature of $25.0 \pm 0.1{ }^{\circ} \mathrm{C}$. In all experiments, the test solutions were deaerated with nitrogen.

\section{Result and Discussion}

\subsection{Voltammetric Study of Anthone3 Using Glassy Carb on Electrode and Screen-} Printed Electrode

Cyclic voltammetric studies were carried out using screen-printed electrode modified with anthrone3 (SPE-A) as well as with bare GC electrode in 1:1 water-acetonitrile solution mixture of anthrone3. Voltammograms with both electrodes displayed sharp and distinct peaks of reversible nature for anthrone3. A redox couple was obtained at 0.076 and $0.019 \mathrm{~V}$ and 0.03 and $0.21 \mathrm{~V}$ for SPE-A and anthrone3, respectively, which can be explained on the basis of mechanism shown in Scheme 1. Magnitude of the current for SPE-A (6.4 $\mathrm{mA}$ in anodic region) was about three times the current obtained with GC electrode using anthrone3 solution $\left(10^{-4} \mathrm{M}\right)$ (Figure 1). Experiments with unmodified SPE and GC performed in acetonitrile $(\mathrm{ACN})$ and $\mathrm{ACN}$ :water media did not show any voltammogram. Experiments with unmodified SPE and modified SPEs showed that there is a significant increase in current magnitude due to fast electron transmission between the ionophore and the electrode ink [26-28]. 
Further, voltammograms with SPE showed a cathodic shift of about $100 \mathrm{mV}$ in anodic region and about $50 \mathrm{mV}$ in cathodic region. Both the curves were reproducible and were recorded several times. The differences in shifts in peak potentials (100 and $50 \mathrm{mV}$, respectively, in anodic and cathodic regions) can be explained in terms of the $\Delta \mathrm{E}_{\mathrm{SPE}-\mathrm{A}}$ $(57 \mathrm{mV})$ and $\Delta \mathrm{E}_{\mathrm{GC}}(180 \mathrm{mV})$. The lesser value of $\Delta \mathrm{E}_{\mathrm{SPE}-\mathrm{A}}$ is due to faster electron transfer in SPE than in GC because of very fast charge transfer between the ionophore and ink of the SPE matrix working as the carbon electrode.

\subsection{Solvent Effect}

To understand the effect of different solvent mixtures, experiments were conducted to record voltammograms for both SPE-A and anthrone3 in solution phase. The wateracetonitrile solvent mixtures were taken in different volume ratios of 10:0, 7:3, and 1:1 (Figures 2 and 3). The results with 1:1 water:acetonitrile were the most reproducible and stable. The voltammograms in this selected solvent mixture using GC electrode showed only one redox couple and a cathodic shift of about $100 \mathrm{mV}$ from that of peak potential in pure acetonitrile medium.

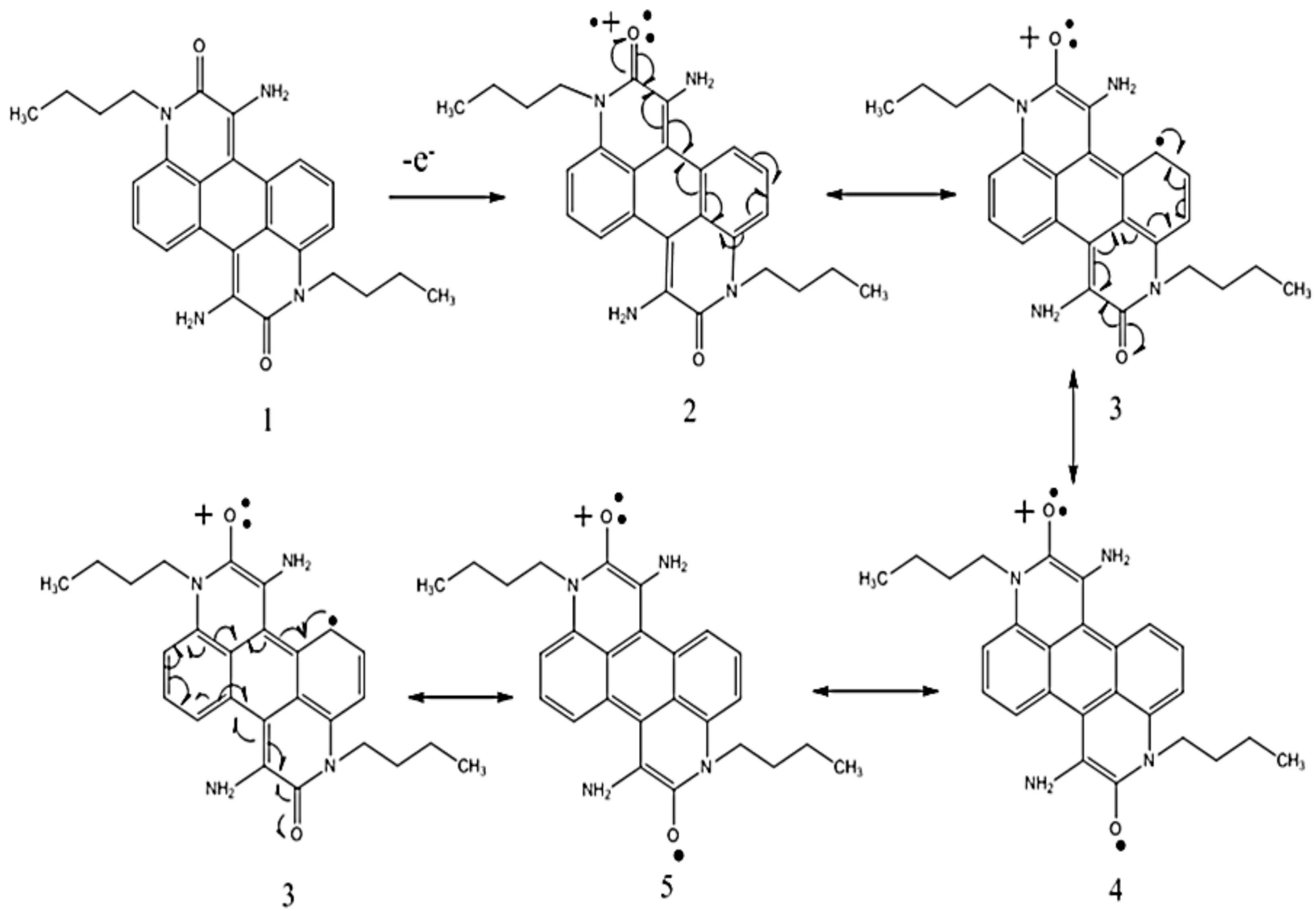

Scheme 1. Resonance stabilization of substituted anthrone3 through conjugation of lone pairs on oxygen of -CO group. 

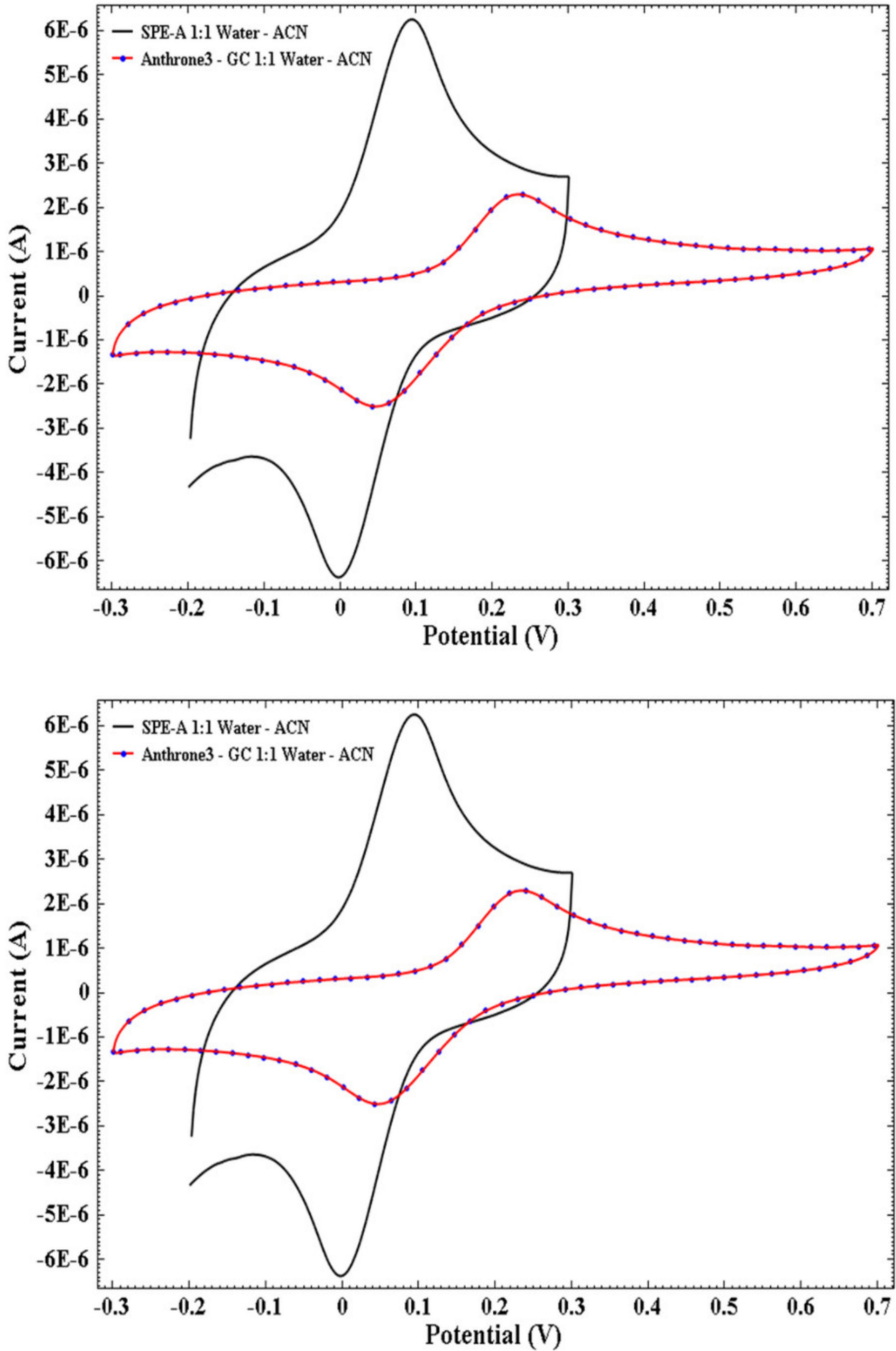

Figure 1. Cyclic voltammogram of anthrone3 $\left(10^{-4} \mathrm{M}\right.$, solution phase) with glassy carbon (GC) as working electrode and screen-printed electrode modified with anthrone3 (SPE-A), in 1:1 water-ACN solvent system. Scan rate: $0.02 \mathrm{~V} \mathrm{~s}^{-1}$; supporting electrolyte: $0.1 \mathrm{M} \mathrm{KCl}, \mathrm{pH} 7, \mathrm{E}$ vs. $\mathrm{Ag} / \mathrm{AgCl}$ ). 


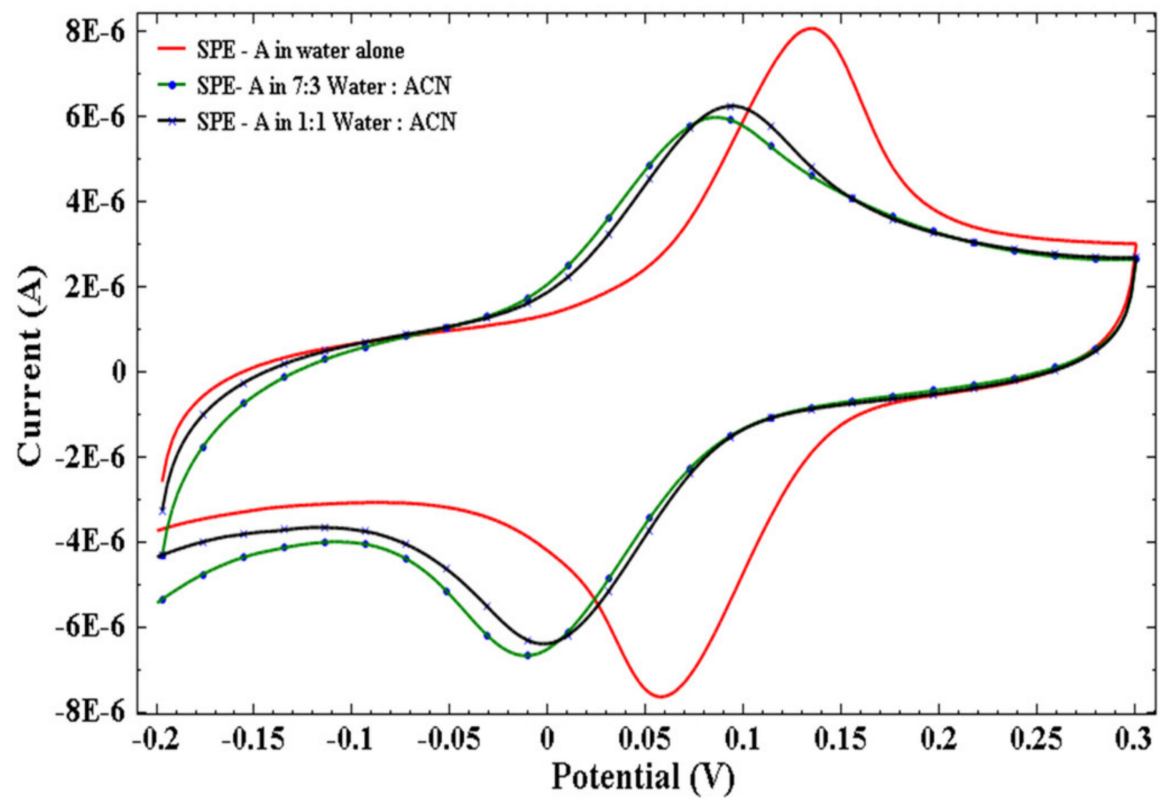

Figure 2. Effect of solvent system on anthrone3-modified screen-printed electrode (scan rate $0.02 \mathrm{~V}$ $\mathrm{s}^{-1}$, supporting electrolyte $0.1 \mathrm{M} \mathrm{KCl}, \mathrm{pH}$ 7, E vs. $\mathrm{Ag} / \mathrm{AgCl}$ ).

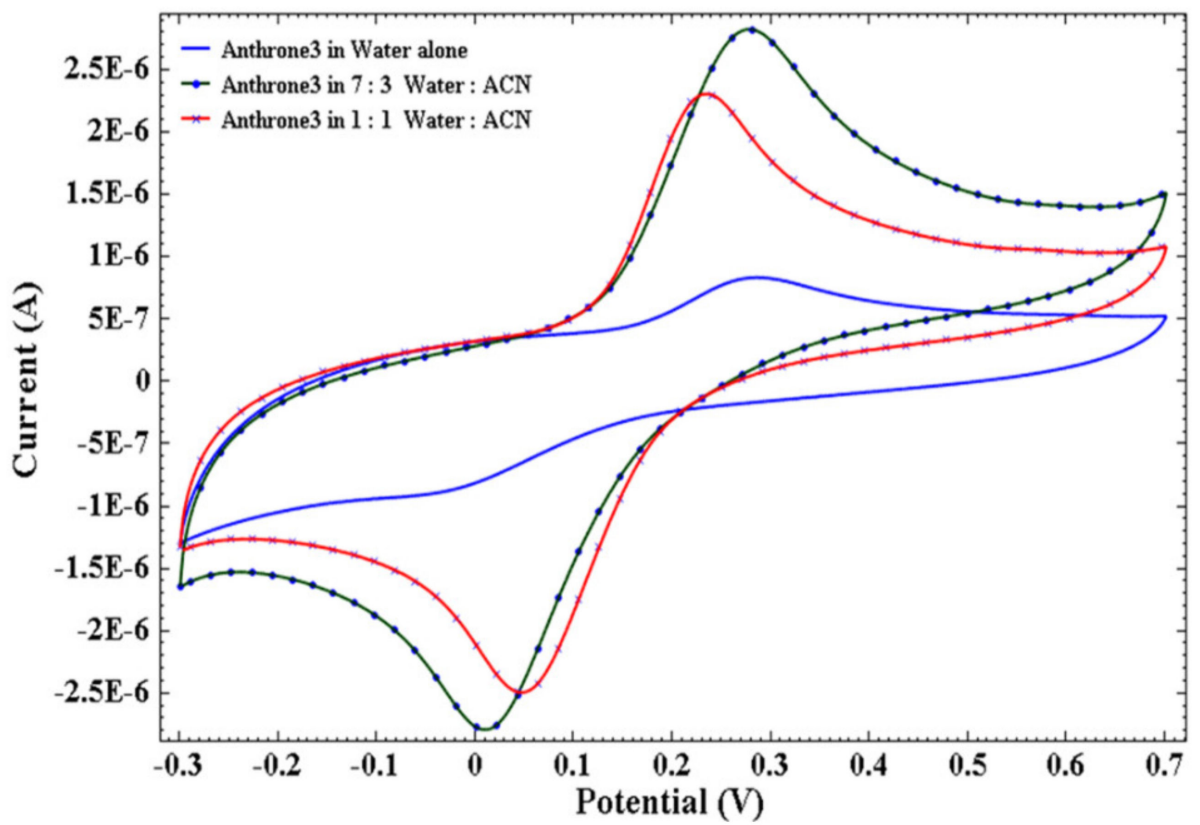

Figure 3. Effect of solvent system on anthrone3 (solution phase) with GC as working electrode (scan rate $0.02 \mathrm{~V} \mathrm{~s}^{-1}$, supporting electrolyte $0.1 \mathrm{M} \mathrm{KCl}, \mathrm{pH}$ 7, $\mathrm{E}$ vs. $\mathrm{Ag} / \mathrm{AgCl}$ ).

In addition, the oxidation peak at $0.98 \mathrm{~V}$ was found quenched in the solvent mixture medium. Similar behaviour was observed with SPE-A but with increased current magnitude. This voltammetric behaviour in the solvent mixture may be due to high dielectric constant of water, which was involved in hydrogen bonding with anthrone3 resulting in its stabilization to the extent that the second peak is not observed at all, accompanied with shifting of the redox couple to the lower potential. On the basis of better stability and reproducibility of voltammograms in water-acetonitrile solvent mixture (1:1), all subsequent studies were carried out in this solvent mixture composition. 


\subsection{Effect of Scan Rate}

Peak currents of anodic waves were plotted against square root of scan rates separately for modified screen-printed electrode (Figure 4A) and anthrone3 in solution phase using GC electrode (Figure 4B).
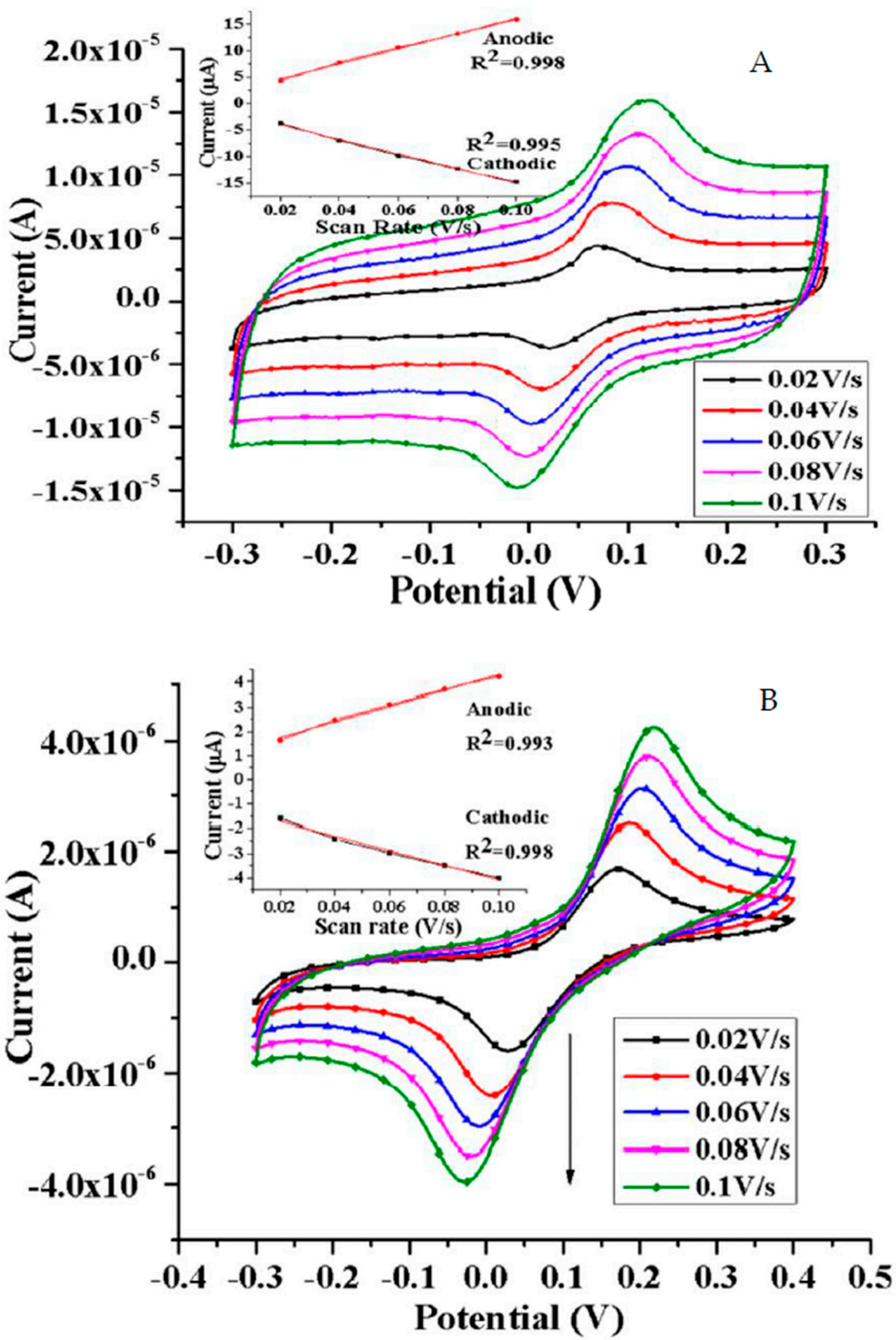

Figure 4. Cyclic voltammograms of SPE-A (A) and anthrone3 (B) in 1:1 water-ACN at different scan rates (supporting electrolyte $0.1 \mathrm{M} \mathrm{KCl}, \mathrm{pH} 7, \mathrm{E}$ vs. $\mathrm{Ag} / \mathrm{AgCl}$ ). (Plots in the inset show current plotted as a function of square root of the scan rate). 
A linear plot between peak current and the square root of scan rate indicated a diffusion-based process. As per the Randles-Sevcik Equation (1), for a reversible system peak potential is independent of scan rate and $\Delta E=59 \mathrm{mV} / \mathrm{n}$ [29]. It can be seen from Figure $4 \mathrm{~A}, \mathrm{~B}$ that at lower scan rate, i.e., $20 \mathrm{mV} \mathrm{s}^{-1}$, reversibility conditions are followed (in Table 1 the $\triangle \mathrm{E}$ value for SPE-A is $57 \mathrm{mV}$ ), while at scan rate of $40 \mathrm{mV} \mathrm{s}^{-1}$ and above, response of the electrode tends to be quasi-reversible ( $\Delta \mathrm{E}$ value between 60 and $200 \mathrm{mV}$ ).

$$
I_{p}=\left(2.69 \times 10^{5}\right) n^{3 / 2} A C D v^{1 / 2},
$$

where $I_{p}$ is the peak current (A), $n$ is the number of electrons, $A$ is the area of electrode $\left(\mathrm{cm}^{2}\right), C$ is the concentration $\left(\mathrm{mol} \mathrm{cm}{ }^{-3}\right), D$ is the diffusion coefficient $\left(\mathrm{cm}^{2} \mathrm{~s}^{-1}\right)$, and $v$ is the scan rate $\left(\mathrm{V} \mathrm{s}^{-1}\right)$.

Table 1. Voltammetric data of screen-printed electrode modified with anthrone3 (SPE-A) with different metal ions.

\begin{tabular}{ccccc}
\hline Working Electrode & $\mathrm{E}_{\mathbf{a}}(\mathrm{V})$ & $\mathrm{E}_{\mathbf{c}}(\mathrm{V})$ & $\Delta \mathrm{E}_{\mathbf{p}}=\mathrm{E}_{\mathbf{a}}-\mathrm{E}_{\mathbf{c}}(\mathrm{V})$ & $\Delta \mathrm{E}_{\mathbf{a}}(\mathrm{V})$ \\
\hline SPE-A alone & 0.076 & 0.019 & 0.057 & - \\
\hline SPE-A with $\mathrm{Co}^{2+}$ & 0.071 & 0.011 & 0.060 & 0.005 \\
\hline SPE-A with $\mathrm{Ni}^{2+}$ & 0.081 & 0.021 & 0.060 & -0.005 \\
\hline SPE-A with $\mathrm{Cu}^{2+}$ & 0.104 & -0.232 & 0.336 & -0.028 \\
\hline SPE-A with $\mathrm{Zn}^{2+}$ & 0.073 & 0.011 & 0.062 & 0.003 \\
\hline SPE-A with $\mathrm{Hg}^{2+}$ & 0.122 & -0.071 & 0.193 & -0.046 \\
\hline SPE-A with $\mathrm{Pb}^{2+}$ & 0.112 & 0.047 & 0.065 & -0.036
\end{tabular}

$\mathrm{Ea}=$ anodic peak potential, $\mathrm{Ec}=$ cathodic peak potential, $\Delta \mathrm{Ep}=$ difference of peak potentials, $\Delta \mathrm{Ea}=$ difference of anodic peak potential.

\subsection{Cation Selectivity Behaviour}

Experiments were conducted with SPE-A electrode in presence of different metal ions in 1:1 water-acetonitrile medium. The presence of different metal ions like $\mathrm{Co}^{2+}, \mathrm{Ni}^{2+}$ $\mathrm{Cu}^{2+}, \mathrm{Zn}^{2+}, \mathrm{Hg}^{2+}$, and $\mathrm{Pb}^{2+}$ resulted in the shift of peak potentials to different extents (see Table 1). Taking the magnitude of shift in peak potential as criteria of selectivity, the metal ions can be put in the following decreasing order of selectivity:

$$
\mathrm{Hg}^{2+}>>\mathrm{Pb}^{2+}>\mathrm{Cu}^{2+}>>\mathrm{Ni}^{2+}>\mathrm{Zn}^{2+}>\mathrm{Co}^{2+} \text {. }
$$

Studies were further extended taking different concentrations of $\mathrm{Hg}^{2+}$ ions. It can be observed that the current magnitude of anodic peak at $0.083 \mathrm{~V}$ increases continuously with increasing concentration of $\mathrm{Hg}^{2+}$ ions (Figure 5). The concentration range selected for the study was $5 \times 10^{-6}$ to $3.5 \times 10^{-3} \mathrm{M}$. A similar behaviour was also noticed in the cathodic peak current as well. There was very small shift in peak potential, probably due to quasi-reversible nature of the electrochemical reaction at the cathode. With screen-printed electrode, a selective behaviour for copper ions was also established (Figure 6). A better selectivity for mercury ions over copper ions was noticed with SPE-A. 


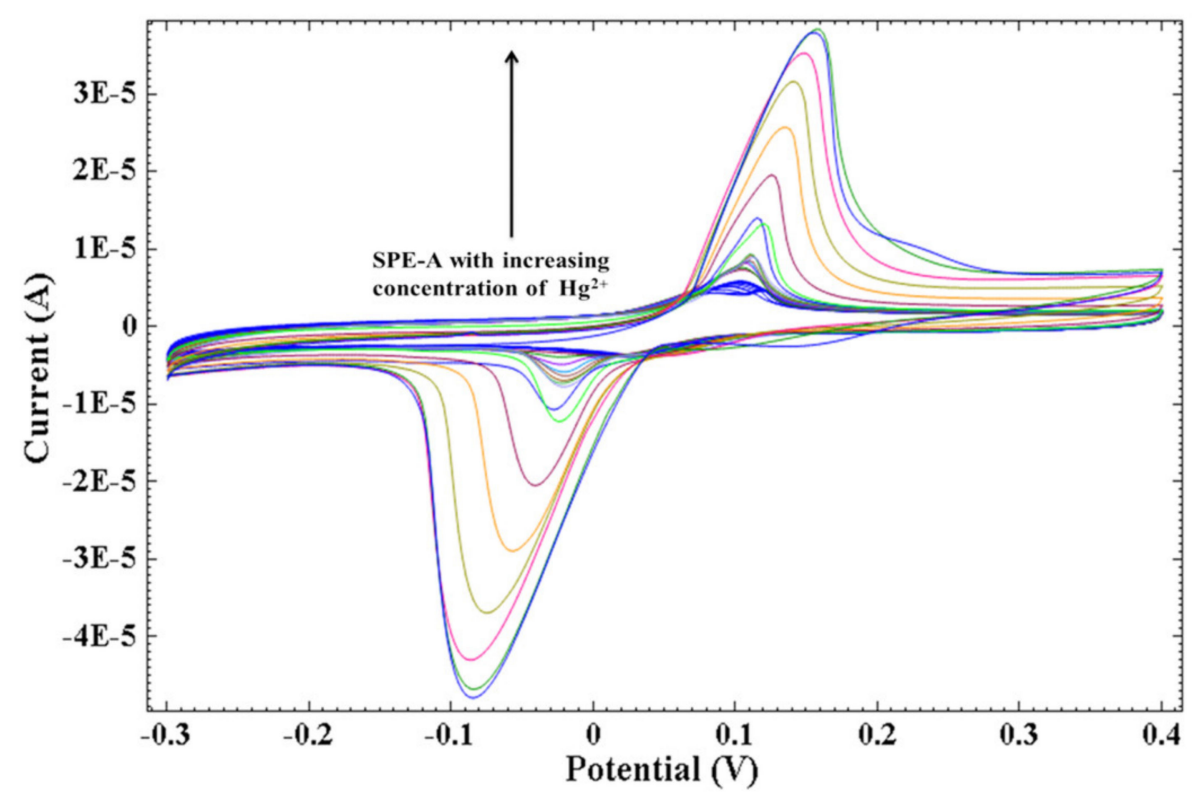

Figure 5. Cyclic voltammograms of SPE-A with different amounts of $\mathrm{Hg}^{2+}$ ions in $1: 1$ water-ACN (scan rate $0.02 \mathrm{~V} \mathrm{~s}^{-1}$, supporting electrolyte $0.1 \mathrm{M} \mathrm{KCl}, \mathrm{pH}$ 7, E vs. $\mathrm{Ag} / \mathrm{AgCl}$ ).

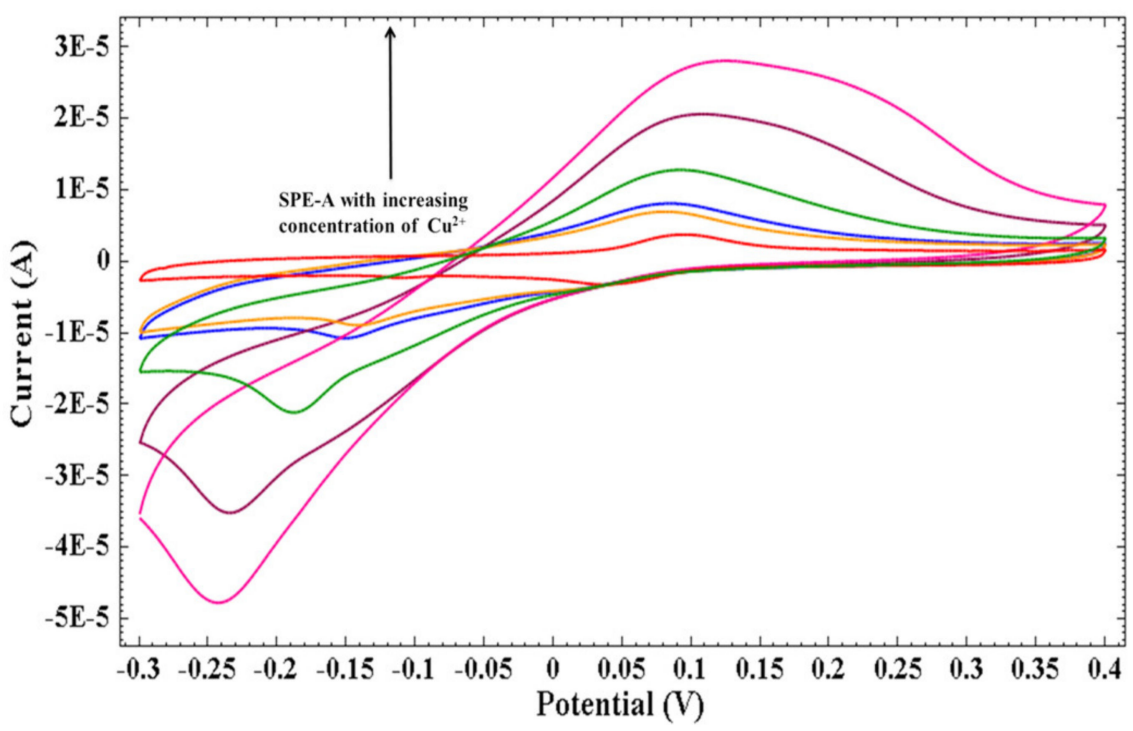

Figure 6. Cyclic voltammograms of anthrone3 (solution phase) with different equivalents of $\mathrm{Cu}^{2+}$ ions in 1:1 water-ACN (scan rate $0.02 \mathrm{~V} \mathrm{~s}^{-1}$, supporting electrolyte $0.1 \mathrm{M} \mathrm{KCl}, \mathrm{pH} \mathrm{7,} \mathrm{E} \mathrm{vs.} \mathrm{Ag} / \mathrm{AgCl}$ ).

Voltammetric study of anthrone3 was also conducted in solution phase (1:1 wateracetonitrile). Which shows sensitivity towards $\mathrm{Hg}^{2+}$ and $\mathrm{Cu}^{2+}$ ions. Even in presence of other heavy metal ions $\mathrm{Pb}^{2+}, \mathrm{Ni}^{2+}, \mathrm{Zn}^{2+}$, and $\mathrm{Co}^{2+}$, anthrone3 shows high sensitivity toward $\mathrm{Hg}^{2+}$ ions. As the concentration of $\mathrm{Hg}^{2+}$ ions increased from $5 \times 10^{-6} \mathrm{M}$, curve crossing in the voltammograms was observed, which shows that ECE mechanism is taking place as curve crossing has been quoted as diagnostic of a series of chemical reactions (presumably electrochemical processes run through a chemical process) occurring within the electrochemical timescale of a cyclic voltammetric scan [30].

\subsection{Interference of Ions}

Interference study was done to know selectivity of both anthrone3 in solution phase and SPE-A. Cyclic voltammograms were run for both these systems in the presence of 
$\mathrm{Hg}^{2+}$ ions. The resulting curves are shown in Figure 7a,b. Even the presence of 10fold concentration of ions like $\mathrm{Co}^{2+}, \mathrm{Ni}^{2+}, \mathrm{Zn}^{2+}$, and $\mathrm{Pb}^{2+}$ did not show any change in voltammetric response of anthrone3 (in solution phase) and SPE-A towards $\mathrm{Hg}^{2+}$ ions, indicating that there is no interference from these cations.
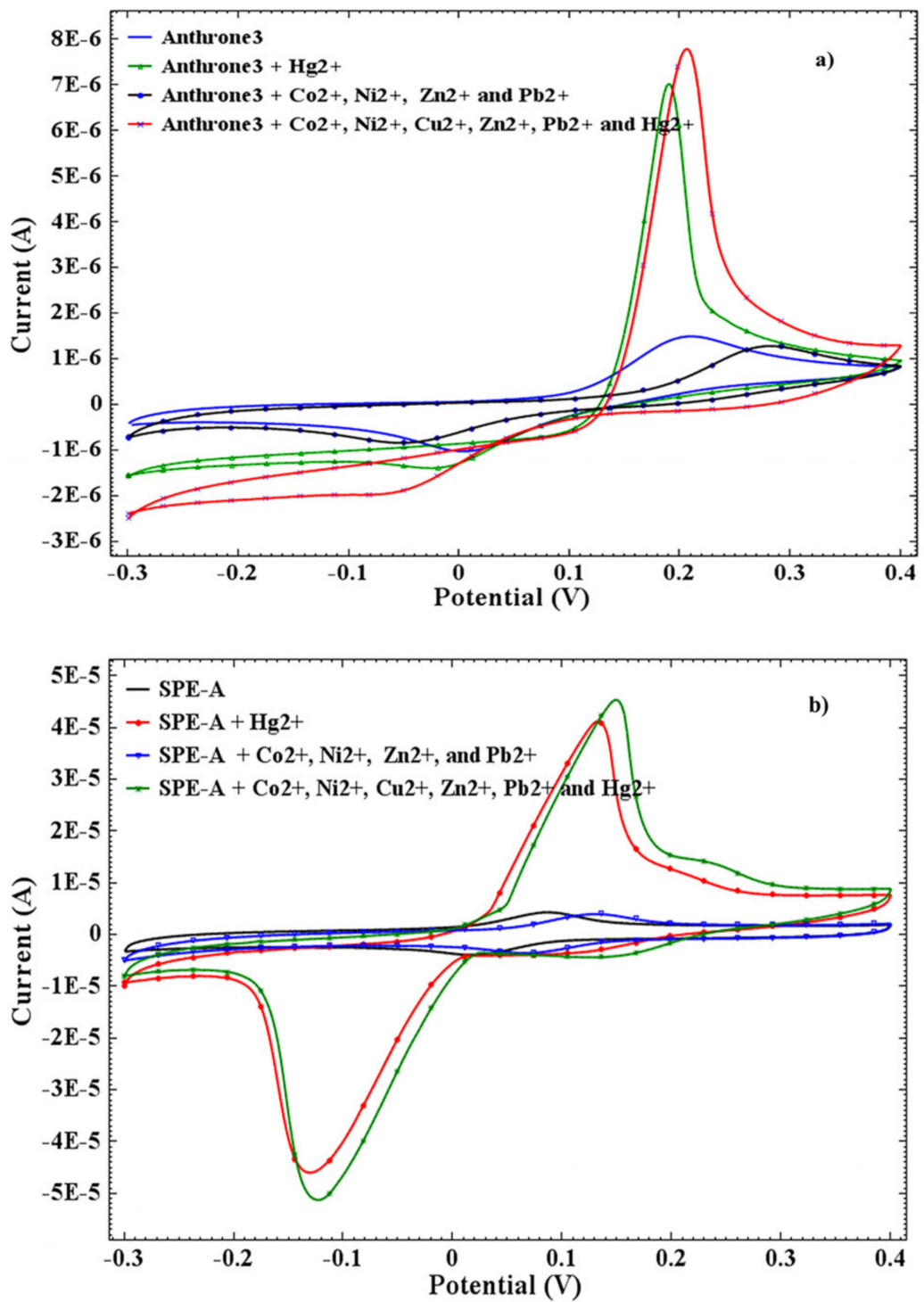

Figure 7. Interference study of (a) anthrone3 in solution phase and (b) SPE-A with different metal ions in 1:1 water-ACN (scan rate $0.02 \mathrm{~V} \mathrm{~s}^{-1}$, supporting electrolyte $0.1 \mathrm{M} \mathrm{KCl}, \mathrm{pH} \mathrm{7,} \mathrm{E} \mathrm{vs.} \mathrm{Ag} / \mathrm{AgCl}$ ).

It can be concluded that both the systems respond selectively towards mercury ions in the presence of many other commonly available cations.

\subsection{Sensitivity ( $L O D$ and $L O Q$ )}

Sensitivity of the method based on SPE was determined from the limit of detection (LOD) and limit of quantification (LOQ) values based on 3-sigma method. A plot of current $(\mu \mathrm{A})$ versus concentration $(\mu \mathrm{M})$ resulted in a straight line. The experiment was repeated 3 times and the representative curve from the 3 sets of data was used for further calculations of LOD and LOQ. Using 3-sigma method, the limit of detection was found to be $0.61 \mu \mathrm{M}$ and limit of quantification value comes out to be $1.86 \mu \mathrm{M}$. However, methods like fluorescence are reported to sense mercury up to $1.0 \mu \mathrm{M}$ level [31], tripodal rhodamine-based chemosensor for $\mathrm{Cu}^{2+}$ and $\mathrm{Hg}^{2+}$ with detection limit of $0.30 \mu \mathrm{M}$ [32], 
and mercury/copper-plated screen-printed electrodes for lead with a detection limit of $0.81 \propto \mathrm{M}[33]$.

\subsection{Regeneration of Screen-Printed Electrodes}

Anthrone3-modified screen-printed electrodes showed highly reversible nature after its exposure to EDTA solution for 5-10 min, after it is used to sense $\mathrm{Cu}^{2+}$ ions in wateracetonitrile medium (Figure 8 ). The disposable electrode was found to respond again as a fresh SPE-A, after its regeneration with EDTA. The electrode was regenerated at least for 3-4 times, after which the response becomes irregular. This observation could not be repeated with $\mathrm{Hg}^{2+}$ ions probably because of greater stability of anthrone3- $\mathrm{Hg}^{2+}$ complex than EDTA- $\mathrm{Hg}^{2+}$ complex (Figure 9). Similar results were obtained with anthrone3 in solution medium (1:1 water-acetonitrile).

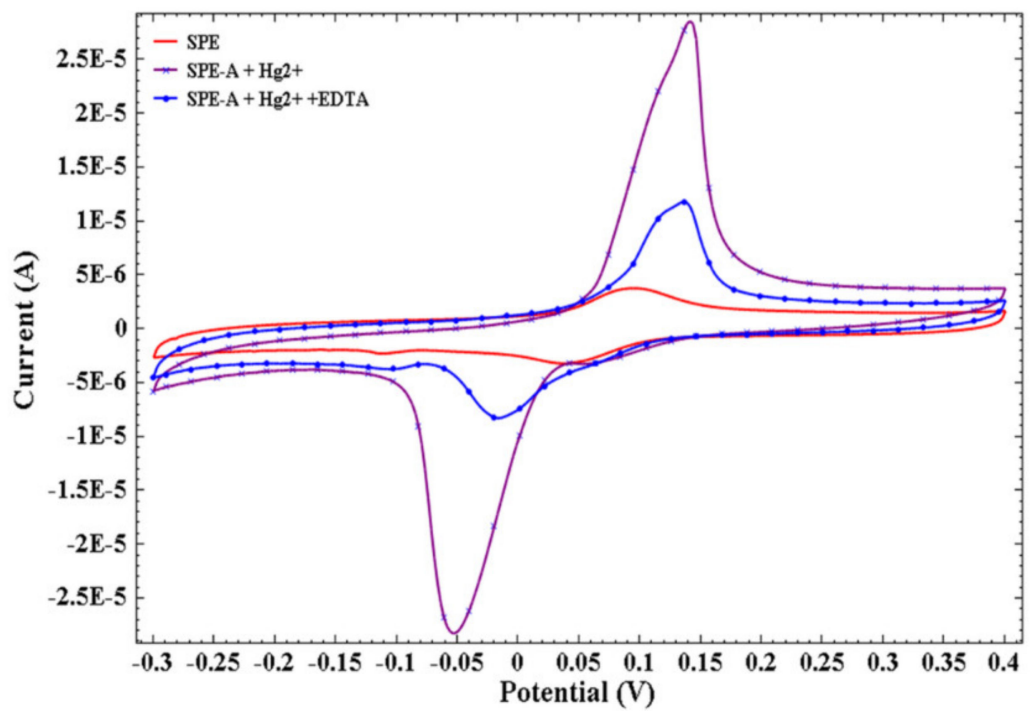

Figure 8. Cyclic voltammograms of SPE-A after treating it with $\mathrm{Hg}^{2+}$ ions and EDTA in 1:1 water$\mathrm{ACN}$ (scan rate $0.02 \mathrm{~V} \mathrm{~s}^{-1}$, supporting electrolyte $0.1 \mathrm{M} \mathrm{KCl}, \mathrm{pH} 7, \mathrm{E} \mathrm{vs}$. $\mathrm{Ag} / \mathrm{AgCl}$ ).

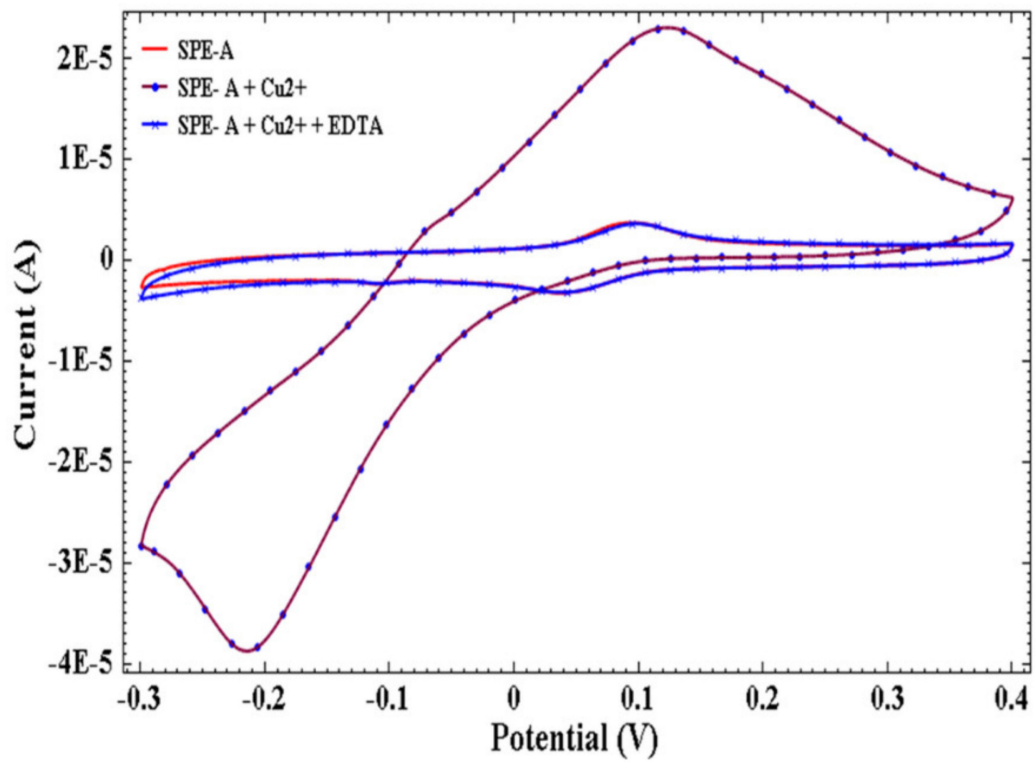

Figure 9. Cyclic voltammograms of SPE-A after treating it with $\mathrm{Cu}^{2+}$ ions and EDTA in 1:1 water$\mathrm{ACN}$ (scan rate $0.02 \mathrm{~V} \mathrm{~s}^{-1}$, supporting electrolyte $0.1 \mathrm{M} \mathrm{KCl}, \mathrm{pH}$ 7, E vs. $\mathrm{Ag} / \mathrm{AgCl}$ ). 


\subsection{SEM Images of EDTA-Treated and Nontreated SPE-A Electrodes}

SEM images were recorded for SPE electrodes modified with anthrone3 (Figure 10). Images of SPE-A were also recorded after sensing mercury and copper ions and their subsequent treatment with EDTA. It can be seen from Figure 11a that white spots encircled in the image are due to the presence of mercury ions, which stay even after treatment with EDTA (Figure 11b) for reasons discussed above. SEM images of SPE with copper ions present as white spots (encircled) (Figure 11c) are found missing in the image (Figure 11d) after treatment with EDTA.

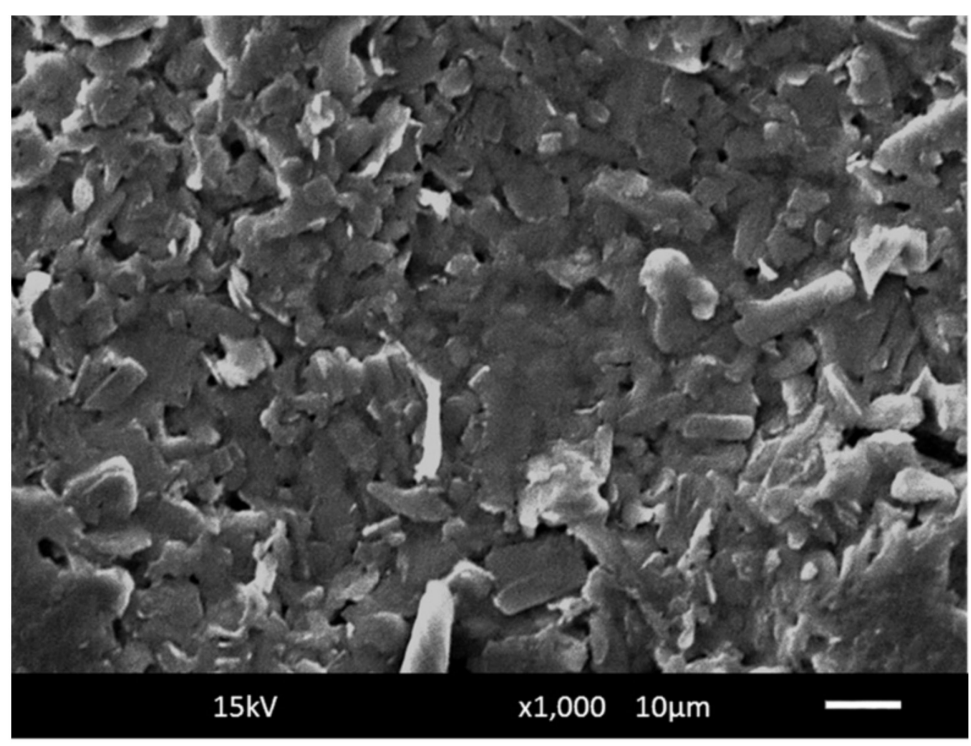

Figure 10. SEM image of anthrone3-modified screen-printed electrode.

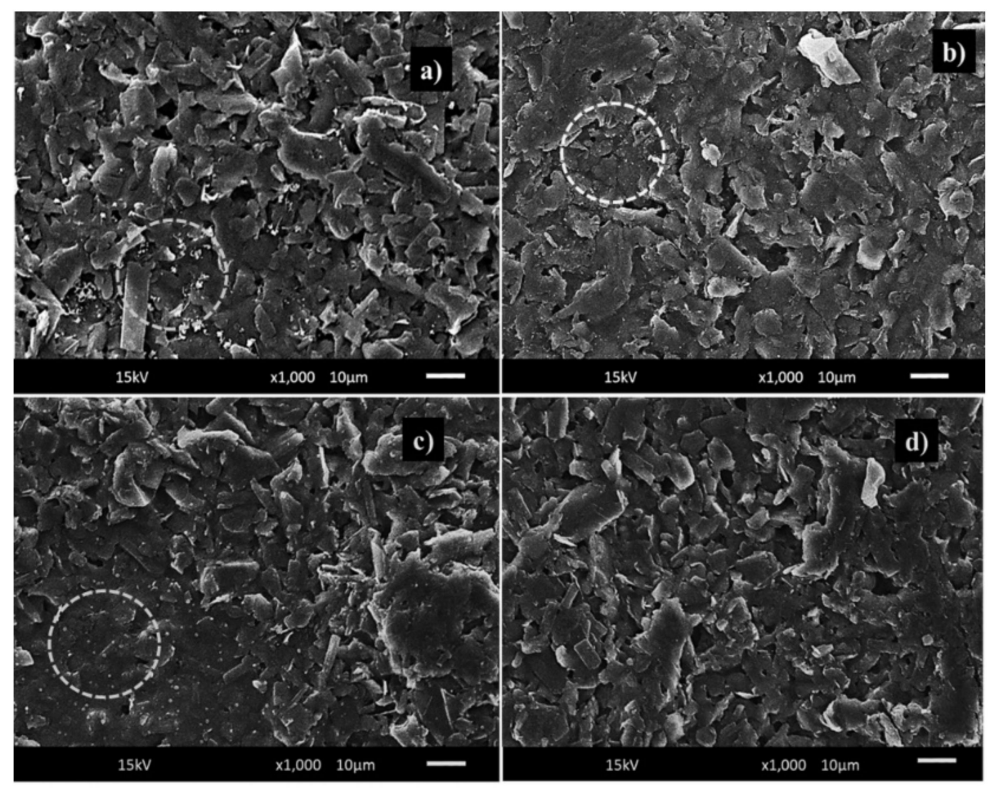

Figure 11. SEM images of anthrone3-modified screen-printed electrode (a) after treatment with $\mathrm{Hg}^{2+}$, (b) $\mathrm{Hg}^{2+}$-treated electrode after treatment with EDTA solution, (c) after treatment with $\mathrm{Cu}^{2+}$, and (d) $\mathrm{Cu}^{2+}$-treated electrode after treatment with EDTA solution.

This hypothesis supports experimental observation that using EDTA-treated SPE after $\mathrm{Cu}^{2+}$ detection could reproducibly give same curve as before. 


\subsection{Validation of Mercury Determination Using SPE-A with AAS}

SPE-A was tested for the analysis of artificial samples of $\mathrm{Hg}^{2+}$ ions. Atomic absorption spectroscopy was used to verify the results obtained with voltammetric method.

Table 2 shows that the results obtained with SPE-A voltammetrically are in complete agreement with the results obtained with AAS for $\mathrm{Hg}^{2+}$ ion.

Table 2. Real-time sample analysis of laboratory tap water and its verification with atomic absorption spectroscopy for $\mathrm{Hg}^{2+}$ ions.

\begin{tabular}{ccc}
\hline Samples & AAS $(\mu \mathbf{M})$ & Voltammetry $($ with SPE-A) $(\mu \mathbf{M})$ \\
\hline Lab tap water & - & - \\
\hline RS1 & 10.0 & 10.5 \\
\hline RS2 & 24.9 & 25.4 \\
\hline RS3 & 35.9 & 36.4 \\
\hline RS4 & 44.9 & 45.4 \\
\hline
\end{tabular}

RS1 = real sample1.

\section{Conclusions}

Screen-printed electrodes modified with Anthrone3 ionophore have been used as voltammetric sensors for heavy metal ions and the results compared with GC based voltamograms Anodic voltamograms were used to study the complexation behaviour of the ionophore with a number of heavy metal ions. Owing to the unique structural symmetry in the molecule it behaved as a highly sensitive probe for mercury ions showing a lower detection limit of $0.61 \propto \mathrm{M}$. Based on the shift in peak potential, different heavy metal ions have been put in decreasing order of selectivity, being more for $\mathrm{Hg}^{2+}$ and least for $\mathrm{Co}^{2+}$ ions. Anthrone3-modified SPE showed far better performance with regard to reproducibility and sensitivity as compared to the glassy carbon electrode. Amongst different compositions of solvents, water-acetonitrile in 1:1 ratio gives the best performance. SPEs are reported for the first time as reproducible voltammetric sensors after treatment with EDTA.

Author Contributions: K.K. and A.K.S. performed experiments, S.K.M. conceptualised the problem and supervised experiments and explained results, A.K. and S.K. synthesised the ionophore while J.P.M. and C.E.B. provided modified SPEs. All authors have read and agreed to the published version of the manuscript.

Funding: This research received no external funding.

Institutional Review Board Statement: Not applicable.

Informed Consent Statement: Informed consent was obtained from all subjects involved in the study.

Data Availability Statement: Not applicable.

Acknowledgments: Authors are thankful to Thapar Institute of Engineering \& Technology, Patiala, for providing research facilities.

Conflicts of Interest: The authors declare no conflict of interest.

\section{References}

1. Grandjean, P.; Weihe, P.; White, R.F.; Debes, F. Cognitive Performance of Children Prenatally Exposed to "Safe" Levels of Methylmercury. Environ. Res. 1998, 77, 165-172. [CrossRef] [PubMed]

2. Renzoni, A.; Zino, F.; Franchi, E. Mercury Levels along the Food Chain and Risk for Exposed Populations. Environ. Res. 1998, 77, 68-72. [CrossRef] [PubMed]

3. Fitzgerald, W.F.; Lamborg, C.H.; Hammerschmidt, C.R. Marine biogeochemical cycling of mercury. Chem. Rev. 2007, 2, 641-662. [CrossRef] [PubMed] 


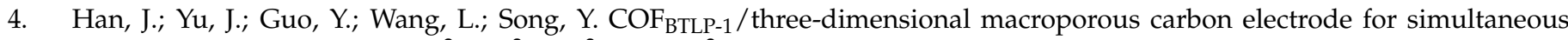
electrochemical detection of $\mathrm{Cd}^{2+}, \mathrm{Pb}^{2+}, \mathrm{Cu}^{2+}$ and $\mathrm{Hg}^{2+}$. Sens. Actu. B 2020, 321, 128498. [CrossRef]

5. Uauy, R.; Olivares, M.; Gonzalez, M. Essentiality of copper in humans. Am. J. Clin. Nutr. 1998, 67, 952S-959S. [CrossRef] [PubMed]

6. Benoit, J.M.; Fitzgerald, W.F.; Damman, A.W. The Biogeochemistry of an Ombrotrophic Bog: Evaluation of Use as an Archive of Atmospheric Mercury Deposition. Environ. Res. 1998, 2, 118-133. [CrossRef]

7. Buica, G.O.; Bucher, C.; Moutet, J.C.; Royal, G.; Saint-Aman, E.; Ungureanu, E.M. Sensing of Mercury and Copper Cations at Poly (EDTA-like) Film Modified Electrode. Electroanalysis 2009, 1, 77-86. [CrossRef]

8. Ghanei-Motlagh, M.; Taher, M.A.; Heydari, A.; Ghanei-Motlagh, R.; Gupta, V.K. A novel voltammetric sensor for sensitive detection of mercury (II) ions using glassy carbon electrode modified with graphene-based ion imprinted polymer. Mater. Sci. Eng. C 2016, 63, 367-375. [CrossRef]

9. Heitzmann, M.; Basaez, L.; Brovelli, F.; Bucher, C.; Limosin, D.; Pereira, E.; Rivas, B.L.; Royal, G.; Saint-Aman, E.; Moutet, J.C. Voltammetric Sensing of Trace Metals at a Poly (pyrrole-malonic acid) Film Modified Carbon Electrode. Electroanalysis 2005, 21, 1970-1976. [CrossRef]

10. Somerset, V.; Leaner, J.; Mason, R.; Iwuoha, E.; Morrin, A. Development and application of a poly (2,2'-dithiodianiline) (PDTDA)coated screen-printed carbon electrode in inorganic mercury determination. Electrochim. Acta 2010, 14, 4240-4246. [CrossRef]

11. Emanuel, C.E.; Ellison, B.; Banks, C.E. Spice up your life: Screening the illegal components of 'Spice' herbal products. Anal. Methods 2010, 2, 614-616. [CrossRef]

12. Mondal, A.; Hazra, A.; Chakrabarty, J.; Bose, K.J.C.; Banerjee, P. Tandem Detection of Sub-Nano Molar Level CN ${ }^{-}$and Hg ${ }^{2+}$ in Aqueous Medium by a Suitable Molecular Sensor: A Viable Solution for Detection of $\mathrm{CN}^{-}$and Development of the RGB-Based Sensory Device. ACS Omega 2020, 5, 6576-6587. [CrossRef] [PubMed]

13. Kampouris, D.K.; Kadara, R.O.; Jenkinson, N.; Banks, C.E. Screen printed electrochemical platforms for pH sensing. Anal. Methods 2009, 1, 25-28. [CrossRef] [PubMed]

14. Šljukić, B.R.; Kadara, R.O.; Banks, C.E. Disposable manganese oxide screen printed electrodes for electroanalytical sensing. Anal. Methods 2011, 3, 105-109. [CrossRef] [PubMed]

15. Montesinos, T.; Pérez-Munguia, S.; Valdez, F.; Marty, J.-L. Disposable cholinesterase biosensor for the detection of pesticides in water-miscible organic solvents. Anal. Chim. Acta 2001, 431, 231-237. [CrossRef]

16. Grennan, K.; Killard, A.J.; Smyth, M.R. Physical characterizations of a screen printed electrode for use in an amperometric biosensor system. Electroanal. Int. J. Devoted Fundam. Pract. Asp. Electroanal. 2001, 13, 745-750. [CrossRef]

17. Hart, A.; Turner, A.; Hopcroft, D. On the use of screen- and ink-jet printing to produce amperometric enzyme electrodes for lactate. Biosens. Bioelectron. 1996, 11, 263-270. [CrossRef]

18. Bernalte, E.; Sánchez, C.M.; Gil, E.P. Determination of mercury in ambient water samples by anodic stripping voltammetry on screen-printed gold electrodes. Anal. Chim. Acta 2011, 689, 60-64. [CrossRef]

19. Yang, F.; Liu, P.; Hao, T.; Wu, Y.; Ma, S.; Hu, Y.; Wang, S.; Guo, Z. Fast-Scan Anodic Stripping Voltammetry for Detection of Pb (II) at Picomolar Level. Russ. J. Electrochem. 2019, 55, 222-228. [CrossRef]

20. Redda, A.R.; Abollino, O.; Malandrino, M.; Squadrone, S.; Abete, M.C.; Berto, S.; Toniolo, R.; Durbiano, F.; Giacomino, A. A Portable Setup for the Voltammetric Determination of Total Mercury in Fish with Solid and Nanostructured Gold Electrodes. Molecules 2019, 24, 1910. [CrossRef]

21. Raril, C.; Manjunatha, J.G. Fabrication of novel polymer-modified graphene-based electrochemical sensor for the determination of mercury and lead ions in water and biological samples. J. Anal. Sci. Technol. 2020, 11, 1-10. [CrossRef]

22. Shtepliuk, I.; Vagin, M.; Yakimova, R. Insights into the Electrochemical Behavior of Mercury on Graphene/SiC Electrodes. C J. Carbon Res. 2019, 5, 51. [CrossRef]

23. Eksin, E.; Erdem, A.; Fafal, T.; Kıvçak, B. Eco-friendly Sensors Developed by Herbal Based Silver Nanoparticles for Electrochemical Detection of Mercury (II) Ion. Electroanalysis 2019, 31, 1075-1082. [CrossRef]

24. Ganjali, M.R.; Rahmani, A.R.; Shokoohi, R.; Farmany, A.; Khazaei, M. A highly sensitive and selective electrochemical mercury (II) sensor based on nanoparticles of $\mathrm{Hg}$ (II)-imprinted polymer and graphitic carbon nitride (g-C3N4). Int. J. Electrochem. Sci. 2019, 14, 6420. [CrossRef]

25. Hallam, P.M.; Kampouris, D.K.; Kadara, R.O.; Banks, C.E. Graphite screen printed electrodes for the electrochemical sensing of chromium(vi). Analyst 2010, 135, 1947-1952. [CrossRef] [PubMed]

26. Mittal, S.K.; Rana, S.; Kaur, N.; Banks, C.E. A voltammetric method for Fe(iii) in blood serum using a screen-printed electrode modified with a Schiff base ionophore. Analyst 2018, 143, 2851-2861. [CrossRef]

27. Rana, S.; Mittal, S.K.; Kaur, N.; Banks, C.E. Pseudo Cavity of Schiff Base Ionophore Incorporated in Screen Printed Electrode for Sensing of Zn (II). J. Electrochem. Soc. 2019, 166, B464-B471. [CrossRef]

28. Rana, S.; Mittal, S.K.; Singh, N.; Singh, J.; Banks, C.E. Schiff base modified screen printed electrode for selective determination of aluminium (III) at trace level. Sens. Actuators B Chem. 2017, 239, 17-27. [CrossRef]

29. Wang, J.; Zhang, Z. Analytical Chemistry; Trans Tech Publications: Zurich, Switzerland, 1994; Chapter 1; pp. 3-66.

30. Fox, M.A.; Akaba, R. Curve crossing in the cyclic voltammetric oxidation of 2-phenylnorbornene. Evidence for an ECE reaction pathway. J. Am. Chem. Soc. 1983, 105, 3460-3463. [CrossRef] 
31. Kim, D.; Yamamoto, K.; Ahn, K.H. A BODIPY-based reactive probe for ratiometric fluorescence sensing of mercury ions. Tetrahedron 2012, 68, 5279-5282. [CrossRef]

32. Zeng, X.; Dong, L.; Wu, C.; Mu, L.; Xue, S.-F.; Tao, Z. Highly sensitive chemosensor for Cu (II) and Hg(II) based on the tripodal rhodamine receptor. Sens. Actuators B Chem. 2009, 141, 506-510. [CrossRef]

33. Zen, J.-M.; Chung, H.-H.; SenthilKumarabc, A. Determination of lead (II) on a copper/mercury-plated screen-printed electrode. Anal. Chim. Acta 2000, 421, 189-197. [CrossRef] 